\title{
The Neuroprotective Effects of Moderate and Regular Caffeine Consumption in Alzheimer's Disease
}

\author{
Xiangyu Zhou $\mathbb{D}^{1}$ and Lin Zhang $\mathbb{D}^{2}$ \\ ${ }^{1}$ School of Food Science and Nutrition, University of Leeds, Leeds, West Yorkshire LS2 9JT, UK \\ ${ }^{2}$ The Key Laboratory for Special Medical Food Process in Hunan Province, Central South University of Forestry and Technology, \\ Changsha, Hunan 410004, China
}

Correspondence should be addressed to Lin Zhang; 29415441@qq.com

Received 21 January 2021; Revised 27 June 2021; Accepted 19 July 2021; Published 17 August 2021

Academic Editor: Si Qin

Copyright ( $\odot 2021$ Xiangyu Zhou and Lin Zhang. This is an open access article distributed under the Creative Commons Attribution License, which permits unrestricted use, distribution, and reproduction in any medium, provided the original work is properly cited.

\begin{abstract}
The increasing numbers of elderly Alzheimer's disease (AD) patients because of a steady increase in the average lifespan and aging society attract great scientific concerns, while there were fewer effective treatments on AD progression due to unclear exact causes and pathogenesis of AD. Moderate (200-500 mg/d) and regular caffeine consumption from coffee and tea are considered to alleviate the risk of $\mathrm{AD}$ and have therapeutic potential. This paper reviewed epidemiological studies about the relationship of caffeine intake from coffee or/and tea with the risk of AD and summarized the caffeine-related AD therapies based on experimental models. And further well-designed and well-conducted studies are suggested to investigate the optimal dosages, frequencies, and durations of caffeine consumption to slow down $\mathrm{AD}$ progression and treat $\mathrm{AD}$.
\end{abstract}

\section{Introduction}

$\mathrm{AD}$ is the most common cause of dementia, which is associated with the physical deterioration of the brain tissue, leading to greater cognitive malfunctions than those of normal brain aging [1]. The incident rate of $\mathrm{AD}$ increases dramatically with age, only $2 \%$ among 65 years of age, $12.7 \%$ among 90 years of age, and $21.2 \%$ among 95 years of age, respectively [2]. And cognitive impairment, characterized by rapid memory and attention decline, is the high-risk factor for $\mathrm{AD}[1]$. Because cognitive impairment is likely to progress to $\mathrm{AD}$ at a rate of $10 \%$ quicker than normal cognitive people at the same age [3], cognitive decline is regarded as a preclinical marker for early dementia. Thus, lowering cognitive decline also indicates a reduction of the risk of AD [4]. Furthermore, cognitive disorders include dementia, cognitive impairment, and cognitive decline [5].

$\mathrm{AD}$ is the consequence of the complex interplay between the genetic and environmental factors, including medical history of diseases and dietary habits [6]. Currently, there are limited efficient pharmacological therapies in reversing the cognitive deterioration and slowing down the progression of $\mathrm{AD}$ [7]. And the permitted six drugs only provide temporary and incomplete symptomatic relief accompanied by severe side effects [8]. Therefore, clinicians considered modifiable risk factors for brain function preservation, such as lifestyle, obesity, diabetes, and hypertension [5]. Because those nonpharmacological interventions are easy to achieve, acceptable, cheap, and without negative consequences at routine levels, they could help reduce healthcare costs at population levels as good prophylaxis of AD [9]. Concerning aspects relating to lifestyle, multiple studies have examined the potential role of phytochemicals in preventing and slowing down progressive pathogenic changes in $\mathrm{AD}$, including flavonoids, phenolic acids, carotenoids, curcumin, resveratrol, and some alkaloids (in the comprehensive reviews $[10,11]$ ). Among them, the effects of caffeine seem to be well researched and documented [12].

Caffeine (1,3,7-trimethylxanthine), a purine alkaloid, is one of the most common and widely consumed psychoactive stimulants daily, exerting its functions on CNS to help antifatigue, increase concentration, and trigger the arousal of 
neurons after short-term consumption [13]. Because chronic low doses of caffeine have been reported to protect against CNS hypoxia and ischemia in rats [14] and gerbils [15, 16], whereas acute caffeine administration exacerbated ischemic neuronal damage in rats with forebrain ischemia produced by bilateral carotid occlusion plus hypotension [14], caffeine may have neuroprotective effects; thus, it is reasonably hypothesized that regular caffeine consumption at a low dose for the long term could help prevent AD.

This article is initially aimed at examining the potential role of constant caffeine consumption in $\mathrm{AD}$ development based on human studies and treating AD based on experimental studies. The second aim is to recommend caffeine dosages, frequencies, and durations that may be beneficial.

\section{Caffeine in AD: Human Study}

Coffee and tea are the two most popular drinks worldwide and are the leading global dietary sources of caffeine [13]. Although caffeine contents vary in a cup of coffee in different studies due to various serving sizes (50-190 ml), types of coffee beans (Arabica or Robusta), preparation methods (boiled or filtered), and serving types (decaffeinated or Italian), the mean caffeine content is generally $90 \mathrm{mg}$ per $230 \mathrm{ml}$ of coffee (a regular cup of coffee is $230 \mathrm{ml}$ ) [17]. Caffeine amounts also vary in a cup of different types of tea. Fresh tea leaves should undergo the diverse degree of fermentation and oxidation of polyphenols during manufacturing; therefore, $100 \mathrm{ml}$ of nonfermented green tea has $15 \mathrm{mg}$ of caffeine on average, and semifermented oolong tea and fermented black tea have $17 \mathrm{mg}$ of caffeine per $100 \mathrm{ml}$ on average (a regular cup of tea is $100 \mathrm{ml}$ ) [18]. If coffee or/and tea consumption could provide appropriate dosages of caffeine to modify the progression of a neurodegenerative disorder that may evolve many years before the emergence of visible clinical symptoms, as appears to be the case with $\mathrm{AD}$, without side effects, they may be recommended as a daily natural complementary therapy for lowering the risk of $\mathrm{AD}$ and slowing down the progression of $\mathrm{AD}$.

This article summarizes 15 human studies including casecontrol studies, cohort studies, cross-sectional studies, and meta-analyses in Table 1, to access the possible effects of caffeine from coffee or/and tea on $\mathrm{AD}$ and suggest optimal dosages, frequencies, and durations of coffee and tea consumption.

2.1. Method. (1) If the selected human studies defined neither the exact caffeine doses in a cup of coffee and tea nor the exact volume of a cup, the caffeine amounts were determined by $90 \mathrm{mg}$ caffeine per cup of coffee (a regular cup of coffee is $230 \mathrm{ml}$ ) [17], $15 \mathrm{mg}$ caffeine per cup of green tea, and $17 \mathrm{mg}$ caffeine per cup of black/oolong tea (a regular cup of tea is $100 \mathrm{ml}$ ) [18]. (2) The average amounts of daily coffee and tea consumption by Canadians were determined by Conway [19] and Lindsay et al. [20], respectively. (3) Because Westerners consume more black tea and rarer green tea than Easterners [21], if the particular types of tea were not identified in the study from the West, tea consumption refers to the mean caffeine amounts of black tea. (4) Tea consumption based on the Eastern study refers to the majority of consumed tea types.
2.2. Caffeine. A retrospective and matched-pair case-control study reported that $\mathrm{AD}$ patients only consumed an average of $73.9 \pm 97.9 \mathrm{mg} / \mathrm{d}$ caffeine as compared to healthy control cases who had $198.7 \pm 135.7 \mathrm{mg} / \mathrm{d}$ during the last 20 years preceding $\mathrm{AD}$ diagnosis. And caffeine exposure during this period could lower the risk of $\mathrm{AD}$ significantly with an $\mathrm{OR}$ of $0.40(95 \% \mathrm{CI}=0.25-0.67)$. Daily caffeine intake was sourced from instant coffee $(60 \mathrm{mg}$ caffeine $/ 142 \mathrm{ml})$, decaffeinated coffee ( $3 \mathrm{mg}$ caffeine/142 $\mathrm{ml}$ ), tea leaf (30 mg caffeine $/ 142 \mathrm{ml})$, instant tea $(20 \mathrm{mg}$ caffeine $/ 142 \mathrm{ml})$, and cola drinks (18 mg caffeine/170 ml) [22]. However, another nested case-control study observed that midlife caffeine intake from coffee $(137 \mathrm{mg} / 227 \mathrm{ml})$, tea $(47 \mathrm{mg} / 227 \mathrm{ml})$, and cola $(46 \mathrm{mg} / 340 \mathrm{ml})$ was not significantly associated with the risk of late-life $\mathrm{AD}$ (25 years later). But the highest levels of caffeine consumption (411.0-1872.5 mg/d) were related to a lower OR of having any of the neuropathological lesion types at autopsy as compared to lower caffeine intake $(\leq 137.0 \mathrm{mg} / \mathrm{d})$ (multivariable-adjusted $\mathrm{OR}=0.45,95 \% \mathrm{CI}=$ $0.23-0.89$, and $P=0.04)$. And the adjusted mean caffeine intake among decedents with $\mathrm{AD}$ lesions was $279 \mathrm{mg}$ as compared to $333 \mathrm{mg}$ among those without lesions $(P=0.10)$ [23]. The 2010 meta-analyses of 11 studies reported that caffeine intake could reduce the risk of $\mathrm{AD}$, with the summary $\mathrm{RR}$ of $0.83\left(95 \% \mathrm{CI}=0.32-2.15, I^{2}=40.5 \%\right)$ [24].

2.3. Coffee. After a 21-year-long period of follow-up observations, the Finnish cohort study reported that participants who consumed 690 to $1150 \mathrm{mg} / \mathrm{d}$ of coffee $(270$ to $450 \mathrm{mg} / \mathrm{d}$ caffeine) at midlife had a decreased risk of late-life AD by $58 \%$ significantly compared with those drinking 0 to $460 \mathrm{mg} / \mathrm{d}$ of coffee ( 0 to $180 \mathrm{mg} / \mathrm{d}$ caffeine, reference). Tea consumption was not associated with a decreased risk of $\mathrm{AD}$ later in life, partially because the majority of participants $(60.5 \%)$ in this study did not drink tea, making statistical power low [25]. A large-scale population-based prospective cohort study among Canadians aged above 65 years consistently reported that daily coffee consumption $(243 \mathrm{mg} / \mathrm{d}$ caffeine [26]) reduced the risk of $\mathrm{AD}$ by $31 \%$ during a 5 -year follow-up, while daily tea drinking (64 mg/d caffeine [19]) was not associated with lowering $\mathrm{AD}$ risk $(\mathrm{OR}=1.12,95 \%$ $\mathrm{CI}=0.78-1.61)$ [20]. Furthermore, a multiethnic cohort study among persons aged above 45 years old reported that, during an average of 16.2 years of follow-up, higher coffee intake (above 2 cups/d, above $180 \mathrm{mg} / \mathrm{d}$ caffeine) lowered the risk for all-cause death, with an HR of 0.82 , as compared to $1 \mathrm{cup} / \mathrm{d}$ ( $\mathrm{HR}=0.88,95 \% \mathrm{CI}=0.85-0.91)$. But only lower coffee consumption (1 cup/d, $90 \mathrm{mg} / \mathrm{d}$ caffeine) had a marginally positive association with the risk of $\mathrm{AD}(\mathrm{HR}=0.90$, $95 \% \mathrm{CI}=0.71-1.14)$ as compared to a negative effect by higher coffee consumption (above 2 cups/d, $180 \mathrm{mg} / \mathrm{d}$ caffeine) [27]. Another large population-based cohort study of old Swedish adults (mean age of 83.2 years) reported that there were no associations of coffee consumption $(177 \mathrm{mg} / \mathrm{d}$ caffeine) and risk of dementia during a mean follow-up of 12.6 years [28]. However, the 2007 meta-analyses of 4 observational studies reported that coffee consumption could significantly reduce $\mathrm{AD}$ risk in comparison with nonconsumers with a pooled risk estimate of 0.73 (95\% CI 


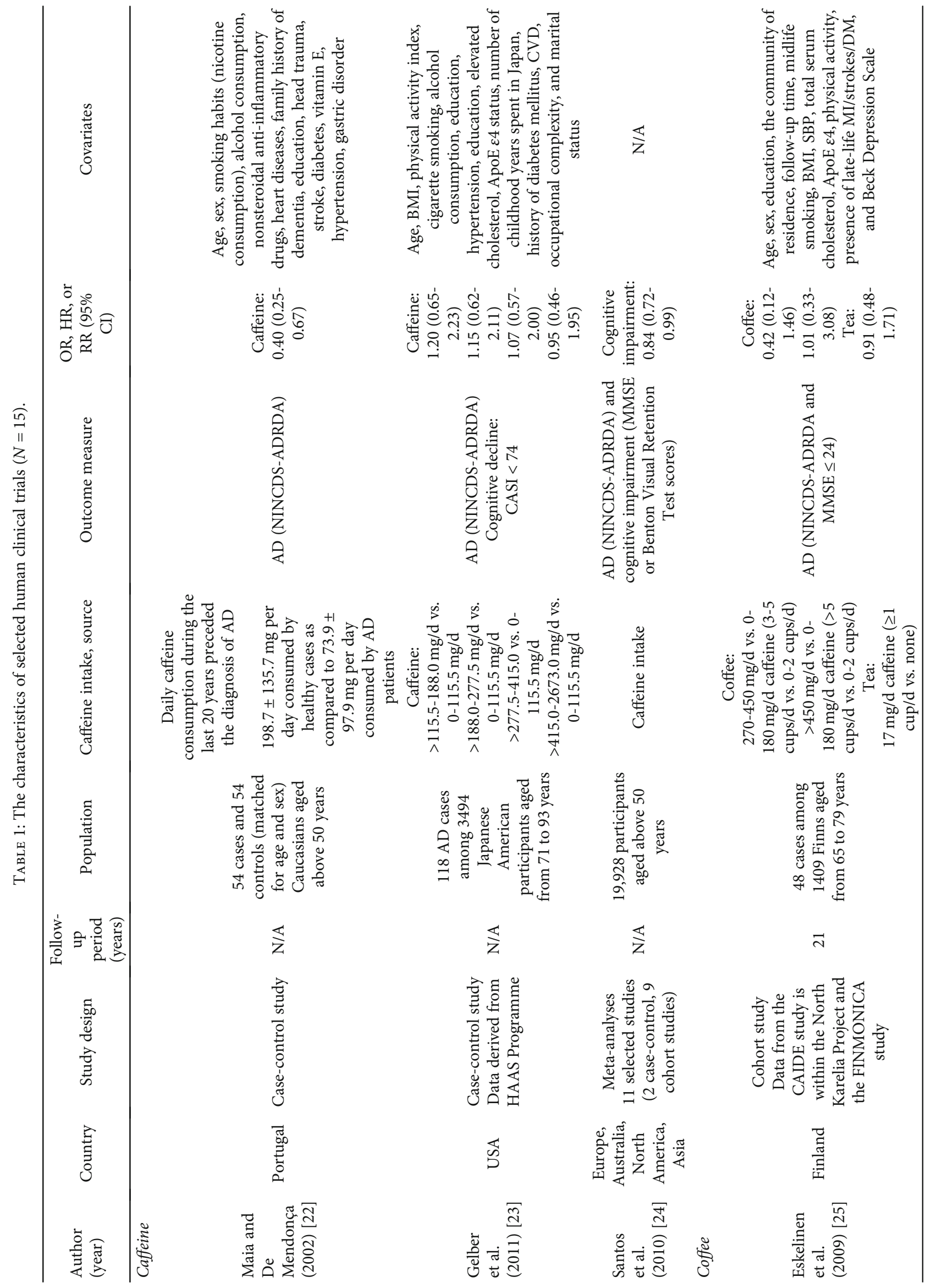




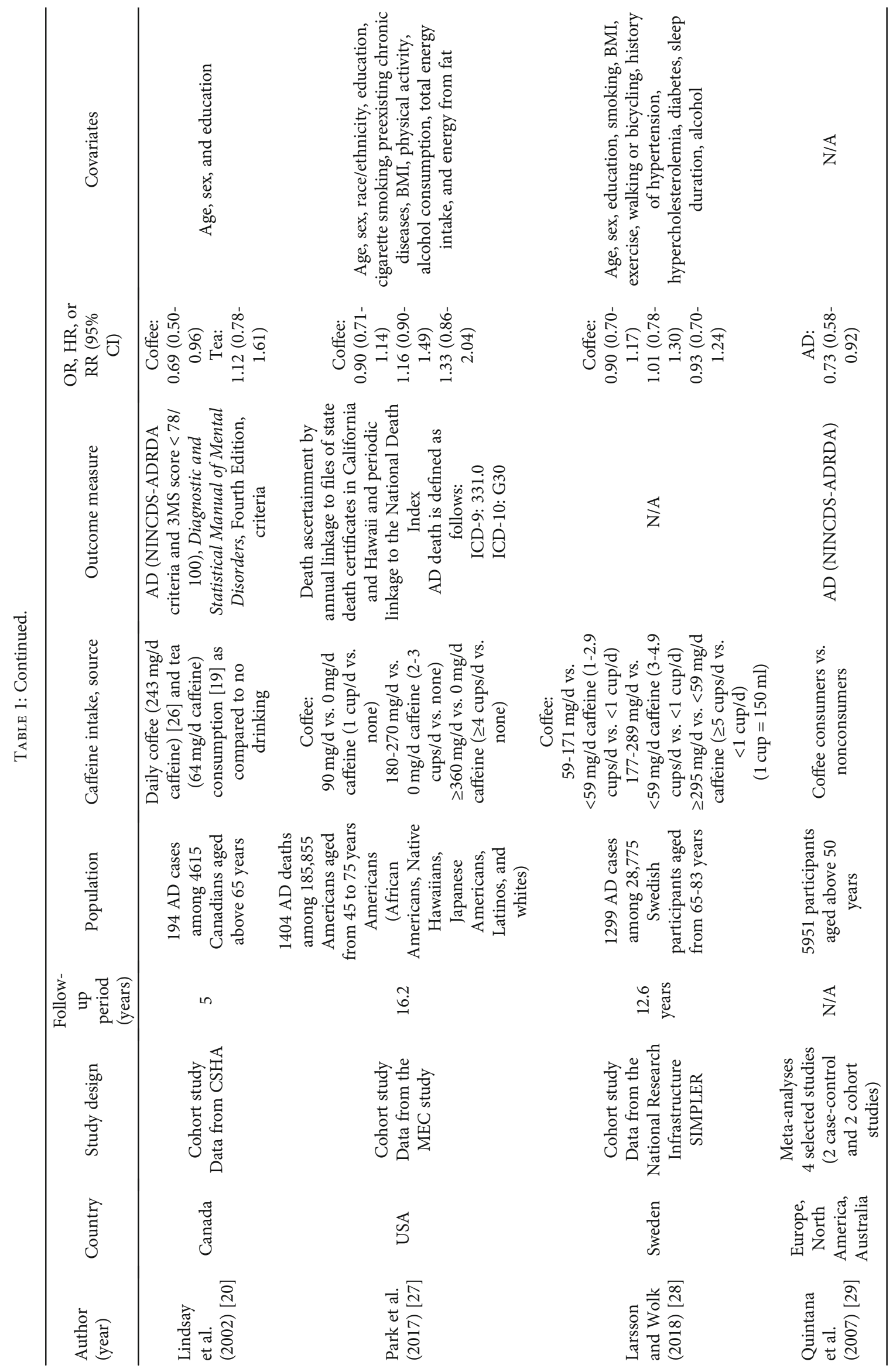




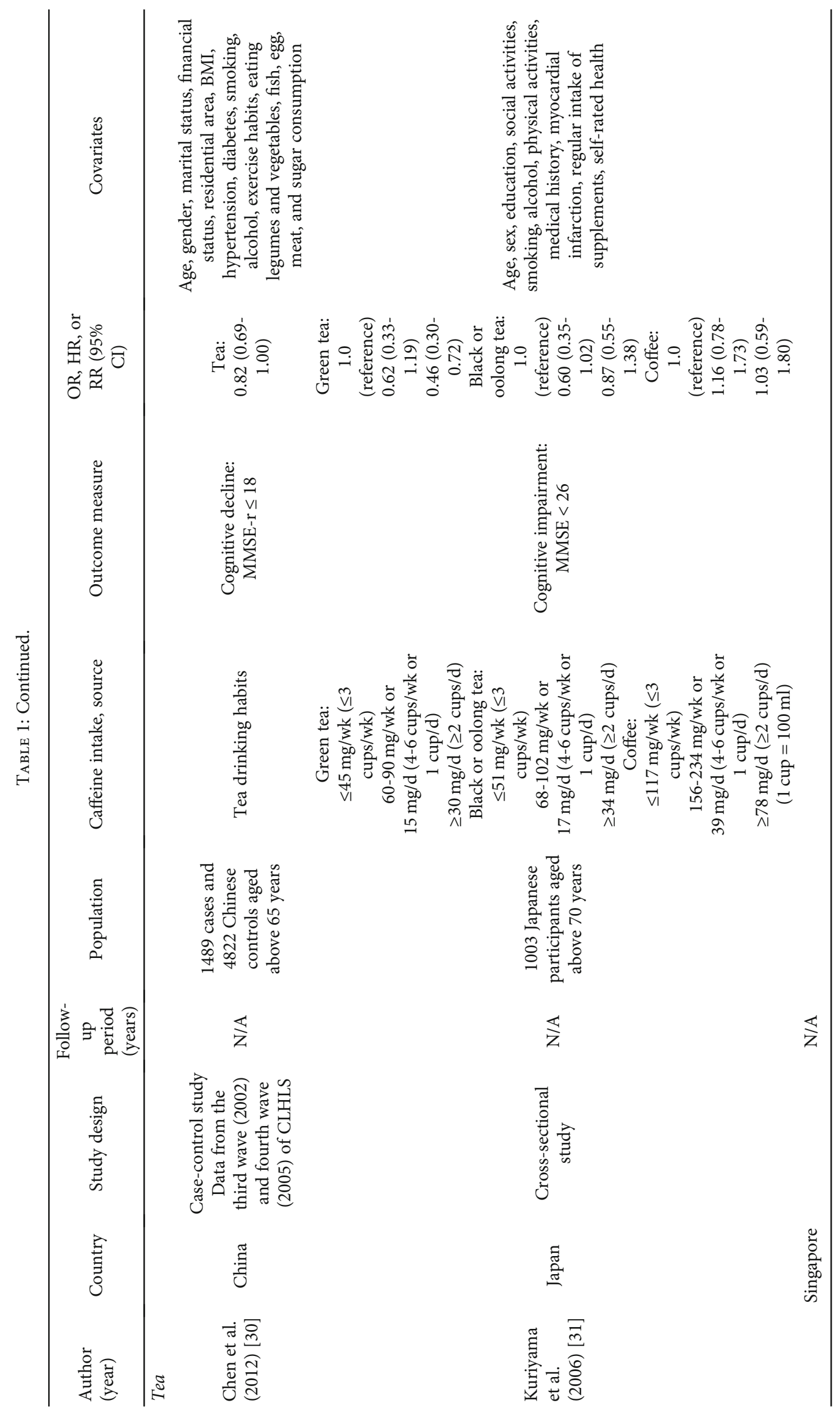




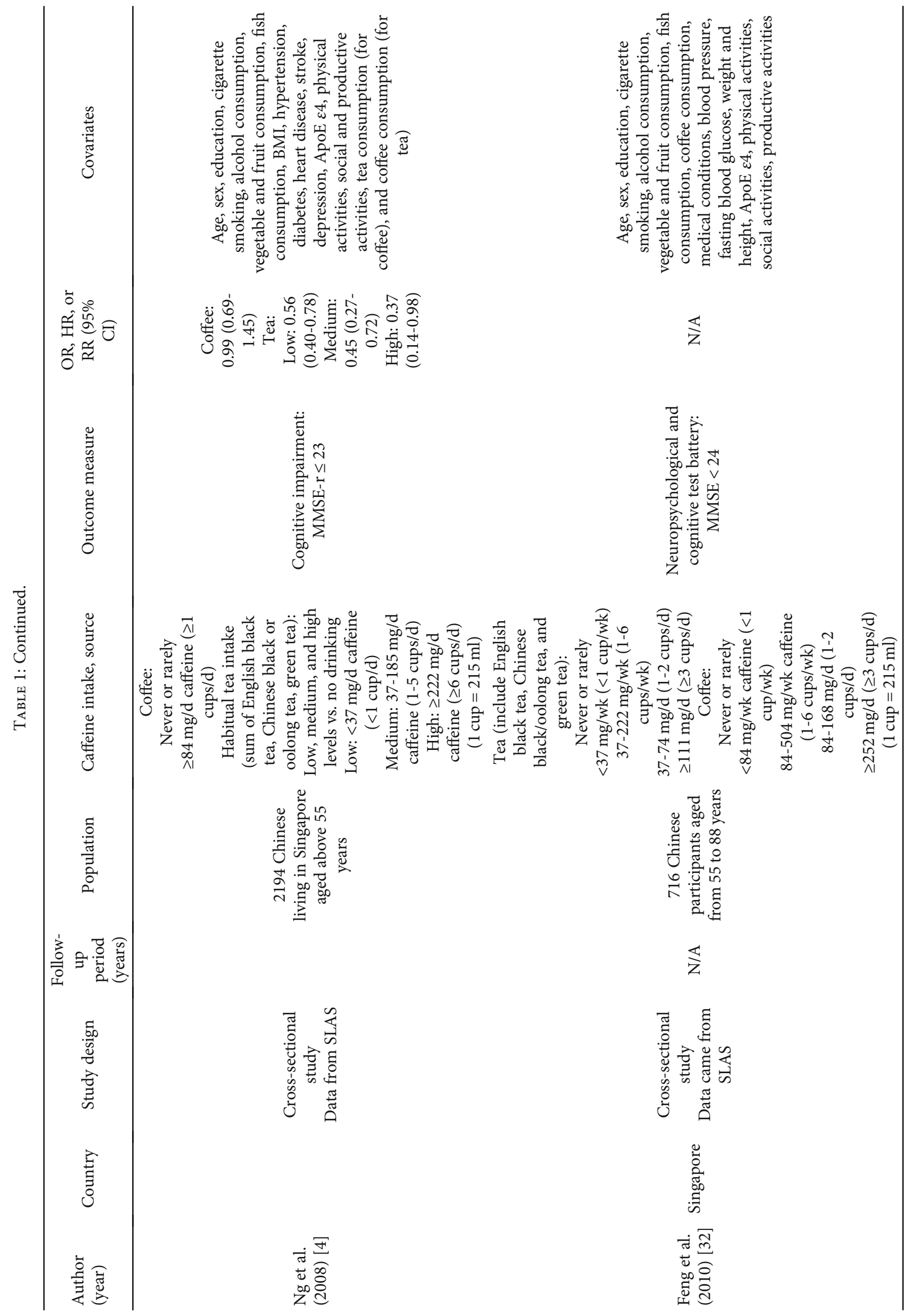




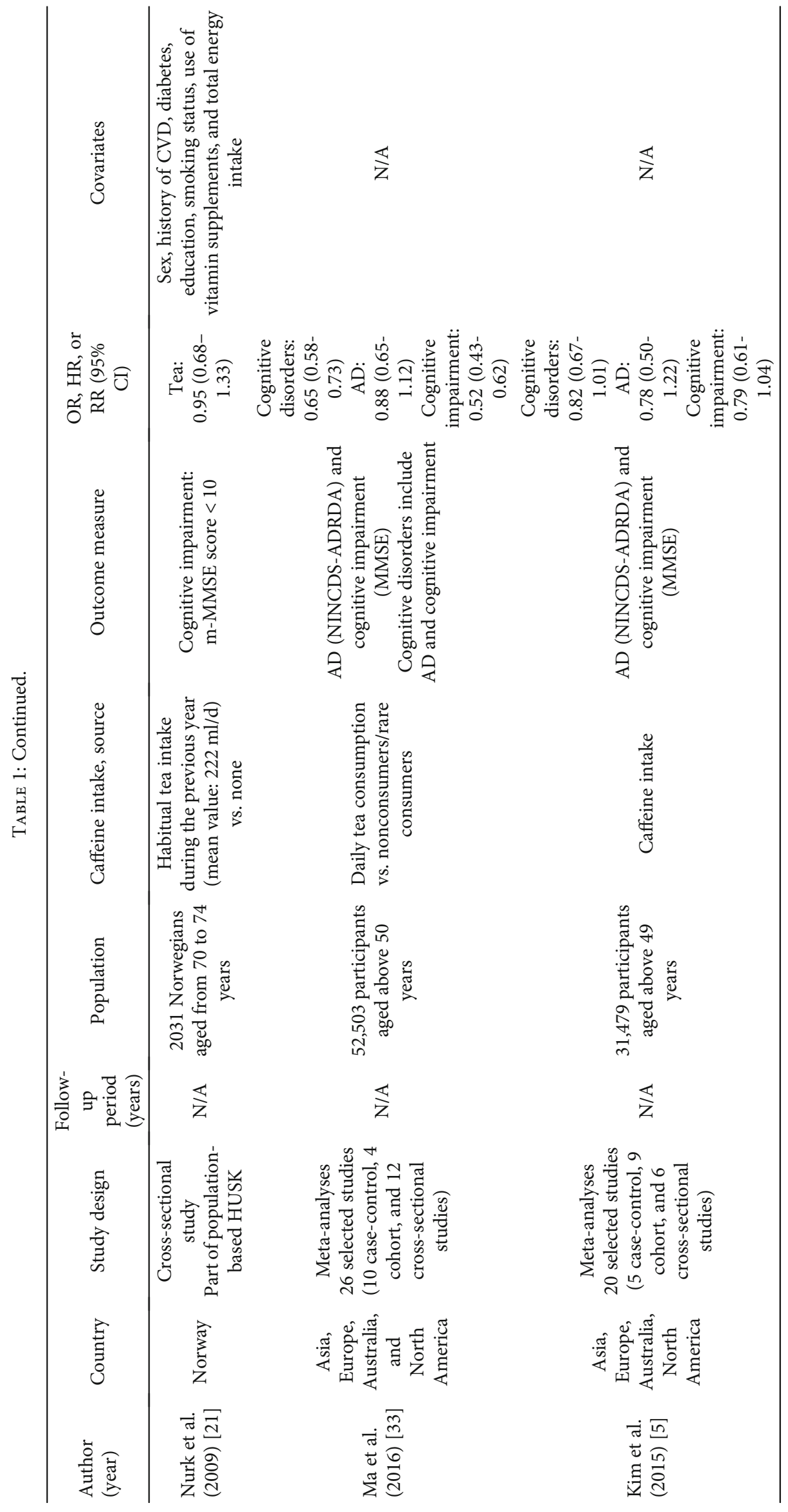


$=0.58-0.92$ ), in a highly significant heterogeneity (chisquared: 13.6, $P<0.01$ ) [29].

2.4. Tea. A national population-based prospective nested case-control study on illiterate elderly Chinese subjects reported a significant inverse relationship between dietary habits of tea drinking and cognitive decline $(\mathrm{OR}=0.82$, 95\% CI $=0.68-1.00$, and $P=0.0468$ ) [30]. And the community-based cross-sectional study among elderly Japanese subjects aged above 70 years also reported an inverse dose-dependent response between green tea consumption and prevalence of cognitive impairment. Subjects who consumed over $200 \mathrm{ml} / \mathrm{d}$ green tea $(30 \mathrm{mg} / \mathrm{d}$ caffeine) and $100 \mathrm{ml} / \mathrm{d}$ (15 mg/d caffeine) had a significantly lower cognitive impairment risk by $54 \%$ and by $38 \%$, respectively, as compared to below $300 \mathrm{ml} / \mathrm{wk}$ ( $45 \mathrm{mg} / \mathrm{wk}$ caffeine, reference) $(P=0.0006)$. However, a weaker association was observed for black or oolong tea consumption with the risk of cognitive impairment, and there was a null association between coffee consumption and the risk of cognitive impairment [31]. On the contrary, in the Singaporean cross-sectional study, participants habitually consumed vastly more black or oolong tea than green tea. Thus, the more inverse relation of black or oolong tea consumption with cognitive impairment was found as compared to green tea. And a higher intake corresponded to a lower risk of cognitive impairment, with an OR of $0.46(95 \% \mathrm{CI}=0.31-0.68)$ for above $215 \mathrm{ml} / \mathrm{d}$ $(37 \mathrm{mg} / \mathrm{d}$ caffeine) and an OR of $0.55(95 \% \mathrm{CI}=0.38-0.79)$ for occasional intake. No significant associations were found between coffee intake and cognitive status [4]. And another Singaporean cross-sectional study among Chinese elders aged above 55 years reported that total tea consumption $(34 \mathrm{mg} / \mathrm{d}$ caffeine) was related to better performance on global cognition (MMSE) $(B=0.055, \mathrm{SE}=0.026$, and $P=$ $0.03)$ and memory improvement $(B=0.031, \mathrm{SE}=0.012$, and $P=0.01$ ). The neuroprotective effects of tea consumption on cognitive function were not limited to a particular tea type. As $45.8 \%$ of participants consumed Chinese black/oolong tea, 37.6\% consumed English black tea and $21.6 \%$ had green tea. However, no association was found between coffee intake and cognitive function, as well as a decrease in $\mathrm{AD}$ risk [32]. Another cross-sectional study among elderly Norwegians (aged 70-74 years) observed that habitual tea consumers who consumed a mean value of $222 \mathrm{ml} / \mathrm{d}(37 \mathrm{mg} / \mathrm{d}$ caffeine) black tea during the previous years had better cognitive performance than nonconsumers, examined by cognitive tests other than MMSE. And the sharpest dose-response effect of tea was up to $200 \mathrm{ml} / \mathrm{d}$ on cognitive performance, after which it tended to plateau [21]. Meanwhile, a metaanalysis of 26 studies (predominately Chinese studies) showed that tea drinking was significantly associated with a decreased risk of cognitive disorders in the elders $\left(\mathrm{OR}=0.65,95 \% \mathrm{CI}=0.58-0.73\right.$, and $\left.I^{2}=78.8 \%\right)$ as compared to nonconsumers or rare consumers, partially owning to neuroprotective effects of caffeine components in tea. There were elusive findings of the relationship between tea intake and $\mathrm{AD}$ in the subgroup analysis $(\mathrm{OR}=0.88,95 \% \mathrm{CI}$ $=0.65-1.12)$ due to the lack of included studies, especially non-Chinese studies [33]. On the contrary, a meta-analysis of 20 studies concluded $5 \mathrm{AD}$-related studies, which reported that caffeine intake from coffee or tea was not significantly associated with the risk of $\mathrm{AD}$ in the random-effects model among elderly participants, with a subtotal OR/RR of 0.78 $\left(95 \% \mathrm{CI}=0.50-1.22, I^{2}=71.0 \%\right)[5]$.

2.5. Discussions on Human Studies. The current studies suggested that caffeine intake may be associated with a lower risk of cognitive disorders including $\mathrm{AD}$, cognitive impairment, and cognitive decline, despite the presence of some inconsistent results. And the neuroprotective effects of caffeine were closely tied to the appropriate frequencies and dosages of consumption. According to Cappelletti et al., low caffeine intake is less than $200 \mathrm{mg} / \mathrm{d}$, moderate caffeine intake is between 200 and $500 \mathrm{mg} / \mathrm{d}$, and high caffeine intake is above $500 \mathrm{mg} /$ day [34]. And the definitions of drinking frequency are regular intake (every day and above 5 times per week) and rare intake (below 2 times per week and never drinking). In line with data from included research showing an inverted U-shaped caffeine dose-response curve [20, 22, 25, 27], regularly intaking moderate caffeine had a better cognitive function and a lower $\mathrm{AD}$ risk. However, low caffeine intake levels had a borderline positive or null relationship with $\mathrm{AD}$ risk [27, 28], and high caffeine consumption may increase the risk of $\mathrm{AD}$ and decrease cognitive performance, especially from coffee intake [27].

Additionally, as the long-term follow-up observations were commonly used in the cohort design. And coffee drinking habits may alter over time, possibly after a significant interval, if the cognitive state or other environmental influences such as lifestyle changes occur. The more obvious protective effects of caffeine from coffee against $\mathrm{AD}$ were more likely to be reported in studies with shorter follow-up as cognition-impaired patients would reduce their daily coffee intake compared to healthy participants, just like the study conducted by Lindsay et al. of 5 years [20] compared with that by Larsson and Wolk of 12.3 years [28].

Coffee, which is more frequently consumed in Western countries than tea as a more popular beverage in Eastern countries, contains much higher amounts of caffeine than any type of tea [25]. Studies in Western countries consistently reported that coffee had neuroprotective effects but null associations of tea consumption, while Eastern countries found the opposite. The neuroprotective effects of tea consumption may be more related to the abundant tea flavonoids (catechins), especially EGCG in green tea and theaflavins in black tea, rather than the stimulant effect of scarce caffeine contents [32]. Furthermore, diversities connected to the ratio of tea leaves to hot water (the boiling way) and the reuse habits of the same tea leaves several times in East Asia in comparison with single-use coffee also make a difference in the analysis between the exact dosage of caffeine and positive neuroprotective effects [35]. And the amounts of caffeine intake from tea also depend on social and cultural diversities. For example, Japanese subjects consume vastly green tea ( 2 cups of green tea per day; one cup is $100 \mathrm{ml}$ ) as a social activity, while Chinese subjects consume a range of tea (more black/oolong tea) [4], resulting in inconsistent results about protective effects of different types of tea among 
Japanese and Chinese subjects. Furthermore, because Westerners consume more black tea and rarer green tea than Easterners, a European study observed that habitual black tea consumption could lower the risk of $\mathrm{AD}$ but the plateau effects were up to $200 \mathrm{ml} / \mathrm{d}$, even corresponding to the neuroprotective effects of lower caffeine amounts but in a habitual intake. And, by meta-analysis, which predominately had summarized Chinese studies, partially due to neuroprotective effects of caffeine in tea, tea consumption could reduce the risk of cognitive disorders in elders compared to nonconsumers or rare consumers [33]. It is thus reasonably assumed that the true association and interplay of flavonoids and caffeine with neuroprotection effects were underestimated. And all the studies on the neuroprotective effects of tea but not coffee were cross-sectional studies, with the results confined by the inference of a temporal causal relation between coffee and tea consumption and prevalence of $\mathrm{AD}$, but the cognition in the old adults is shaped by long-term exposures [4]. Furthermore, the exact neuroprotection of tea for the old adults has also been affected by ambiguous drinking history and durations of tea before the involvement of studies. Further studies are needed to gather data from the long-term consumption of caffeinated coffee and tea to confirm the dose- and frequency-dependent association and the exact time of caffeine when its neuroprotective benefits begin [24]. And more well-defined studies are thus needed to be conducted on different racial/ethnic groups to achieve greater biological plausibility.

Findings of human epidemiological studies may also be influenced by various residual confounders, including smoking and physical activities, as a result of measurement errors or complementary effects of other active substances in coffee or/and tea, including magnesium [36], EGCG [37], and theaflavins [38], indicating human studies did not support the role of caffeine isolation in $\mathrm{AD}$ prophylactics.

Additionally, observational studies focusing on data from the self-reported questionnaires easily introduced biases and created incorrect information, especially in the long-term study. For example, the variability of daily doses of caffeine is increased through occasionally intaking other sources of caffeine like cola without informing the researchers. These exposure misclassifications undermine the methodological approach in particular in recalling it in the long term [24].

Further, different meta-analyses applied different searching strategies, inclusion criteria, and methods to select data for quantitative analysis, resulting in inconsistent findings [24]. And the quality of primary studies is the validity of meta-analysis. None of the double-blind placebo-controlled trials was selected in the meta-analysis that could provide more robust evidence [29], while observationally epidemiological studies were included, which recruited various participants, used different sample sizes, and applied different diagnostic criteria and methods of data analysis. For example, CSHA was a nationwide population-based study [20] while the study of Maia and De Mendonça [22] was a small hospital-based study with only 108 participants. Kuriyama et al. [31] utilized a cutoff value of MMSE of 26 for cognitive impairment diagnosis compared with 23 in $\mathrm{Ng}$ et al. [4]. And meta-analysis has evened up a cup of coffee or tea among all studies, even though there were discrepancies in the definition of caffeine volumes in a cup, making it difficult to validate the dosages of neuroprotective effects of caffeine.

Besides, the main methodological limitation of this study was to neglect the effects of the coffee and tea preparation method, as well as specific coffee and tea types such as decaffeinated coffee and tea. Instead, it used $90 \mathrm{mg}$ caffeine per $230 \mathrm{ml}$ coffee, $15 \mathrm{mg}$ caffeine per $100 \mathrm{ml}$ green tea, and $17 \mathrm{mg}$ caffeine per $100 \mathrm{ml}$ black/oolong tea directly.

In conclusion, it is reasonably suggested that caffeine from moderate and regular caffeine consumption from coffee could impede AD progression but may not for tea intake. And it is required to conduct further well-defined studies on the exact optimal dosages, frequencies, and durations of caffeine from various tea types to minimize the risk of $\mathrm{AD}$.

\section{Caffeine: Pharmacokinetic Profile}

The pharmacokinetic profile of caffeine may be linked to the favorable effects of caffeine on reducing the risk of AD.

After consuming caffeine, caffeine can be absorbed quickly and completely by the gastrointestinal tract, especially in the small intestine, with very high bioavailability (99\%-100\%) [39]. $96.34 \mathrm{mg}$ of caffeine resulted in a maximal plasma concentration of $2.47 \mu \mathrm{g} / \mathrm{ml}$ [40], in the following 30 to 60 minutes [41]. Due to the hydrophobic properties of caffeine, it can also cross through BBB quickly, and then, the brain achieves similar caffeine concentrations as blood, proposing mechanisms of neuroprotection against cognitive dysfunction by oral caffeine intake [41]. Long-term caffeine consumption leads to adaptive changes in the brain, indicating greater betterment on cognitive performance that occurred among the older adults with continuous and regular caffeine consumption [42]. And chronic caffeine treatments could protect against seizures and maintain spatial memory in the mouse model, which was greater than acute caffeine administration [42].

The elimination half-life of moderate amounts of caffeine in systemic circulation has been reported about 5 hours, indicating a quick metabolic rate of caffeine [43]. But the high doses of caffeine over $500 \mathrm{mg}$ have lower elimination rates and thus may affect the cardiovascular system with their positive inotropic and chronotropic effects and the central nervous system with their locomotor activity stimulation and anxiogenic-like effects, accountable for tremor, tachycardia, and anxiety, respectively [34]. But in the habitual caffeine consumers with moderate amounts of caffeine consumption, the acute proarrhythmic effect even caused by high caffeine intake was somewhat attenuated [44]. But regularly intaking high amounts of caffeine leads to caffeine abuse and dependence and can result in caffeine intoxication, which puts individuals at risk for premature and unnatural death [34]. Consequently, caffeine is a central nervous stimulant and should not be used in excess. When used to treat AD, it may require controlling the doses of caffeine below $500 \mathrm{mg} / \mathrm{d}$. 


\section{Pathogenesis of Alzheimer's Disease and Mechanisms of Caffeine Therapies}

AD progressively causes neuronal damage and leads to dementia, which is commonly related to cognitive dysfunction and mental decline, being the third biggest cause of old disabilities and death [45]. This age-related problem is further influenced by population aging and leads to substantial growth in the $\mathrm{AD}$ patient population from 32.5 million in 2021 to 53.3 million by 2030 [46].

The neuropathological hallmarks of $\mathrm{AD}$ are the cerebral extracellular deposition of diffuse and neuritic senile plaques made by $\mathrm{A} \beta$ peptides, the intracellular aggregation of flameshaped NFTs composed of hyperphosphorylated aggregates of the microtubule-associated tau protein, and the selectively large-scale neuronal loss [47]. In understanding the pathology, neurobiological mechanisms underlying $\mathrm{AD}$ have been the key. And the most important changes identified can be explained currently by $\mathrm{A} \beta$ theory, tau protein theory, oxidative stress theory, ApoE4 theory, and adenosine theory.

Meanwhile, human studies do not allow concluding on the role of caffeine itself in the modulation of $\mathrm{AD}$ risk. This article has concluded some experimental studies, especially in the transgenic mouse models of $\mathrm{AD}$, based on the biological alternations observed in these human pathologies, to further investigate the effects of caffeine on $\mathrm{AD}$ development and potential therapeutic effects and dosages.

4.1. A $\beta$ Theory. $\mathrm{A} \beta$ theory is related to the imbalance between the production of $\mathrm{A} \beta$ through proteolysis of APP by $\beta$-secretase and $\gamma$-secretase and the clearance of produced $\mathrm{A} \beta$, which is the triggering event and the most important factor [47].

Newly produced $\mathrm{A} \beta$ comes into a dynamic equilibrium between isoforms soluble $\mathrm{A} \beta_{1-40}$ and deposited $\mathrm{A} \beta_{1-42}$ [48]. And the soluble $\mathrm{A} \beta_{1-40}$ can be cleared out of the brain and entered into plasma down a concentration gradient [48], while the deposited toxic $\mathrm{A} \beta_{1-42}$ is more difficult to be cleared due to greater hydrophobicity, which leads to acquiring the configuration of a $\beta$-pleated sheet and easily clumping themselves together to cause depositions of amyloid neuritic plaques, which disrupt cell functions and lead to AD [49]. By targeting $\beta$-secretase and $\gamma$-secretase to reduce $\mathrm{A} \beta$ production or increasing the clearance speed of deposited $\mathrm{A} \beta_{1-42}$, the progression of $\mathrm{AD}$ might be relieved.

APPsw mice, which were the most prominent transgenic $\mathrm{AD}$ models in animals, can develop substantial levels of brain $\mathrm{A} \beta$ and widespread cognitive impairment with age [50]. The 4-5 weeks of treatment of $1.5 \mathrm{mg} / \mathrm{d}$ caffeine with the human equivalent of $500 \mathrm{mg} / \mathrm{d}$ caffeine in aged APPsw mice (18-19 months old) could stimulate PKA activity which would decrease the hyperactive form of c-Raf-1. This would correct dysregulation of the $c$-Raf- 1 inflammatory pathway, inactivating the $\mathrm{NF}-\kappa \mathrm{B}$ pathway and suppressing $\beta$-secretase expression (Figure 1, Pathway 1). Therefore, the evident $\mathrm{A} \beta$ deposition was reduced by $46 \%$ and $40 \%$ within the entorhinal cortex and hippocampus of $\mathrm{Tg}$ caffeine-treated mice compared to $\mathrm{Tg}$ controls in total, respectively, at 20-21 months of age [51]. Among them, soluble $\mathrm{A} \beta_{1-40}$ and insolu- ble $\mathrm{A} \beta_{1-42}$ levels of aged caffeine-treated $\mathrm{Tg}$ mice were reduced by $25 \%$ and $51 \%$ in the cortex and by $37 \%$ and $59 \%$ in the hippocampus, respectively, when compared with $\mathrm{Tg}$ controls [51]. Also, $1.5 \mathrm{mg} / \mathrm{d}$ caffeine treatment to aged 4-month-old APPsw Tg mice for 5.5 months could reduce $\beta$-secretase by $50 \%$ when following completion of behavioral testing at 9.5 months, then significantly lowering soluble $\mathrm{A} \beta_{1-40}$ production by $37 \%(P<0.05)$ and insoluble $\mathrm{A} \beta_{1-42}$ production by $32 \%(P<0.05)$ as compared to $\mathrm{Tg}$ control mice [41]. GSK-3 $\alpha$ dysregulation is known to $\mathrm{A} \beta$ production by enhancing PS1 mutation which increases the $\gamma$-secretase cleavage of APP activity [52]. Caffeine (1.5 mg/d)-treated Tg mice had normalized PS1 band density ratios, compared with the significantly elevated $\mathrm{Tg}$ control group, after 5.5 months [41]. When treating cultured SweAPP N2a cells with caffeine in a dose-response manner $(0-20 \mu \mathrm{M})$, the maximal effects of decreasing active GSK-3 $\alpha$ levels were achieved at $20 \mu \mathrm{M}$ (the human equivalent of 100-200 mg of caffeine) by 90 minutes [51] (Figure 1, Pathway 1).

4.2. Tau Protein Theory. Although $\mathrm{A} \beta$ theory is regarded to be the beginning of $\mathrm{AD}$ progression, however, it cannot fully explain the etiopathogenesis of AD. Tau protein is the secondary pathogenic event, subsequently leading to neurodegeneration [53]. A $\beta$ exposure promotes GSK-3 $\beta$ overexpression, connected to neurodegeneration-related tau hyperphosphorylation [54]. Indeed, a study reported that chronic lithium (GSK-3 $\beta$ inhibitor) treatment prevented tau hyperphosphorylation in the GSK-3 $\beta$ transgenic mice [55].

Tau is a highly soluble protein whose biological activities are related to microtubules and are regulated by the degree of phosphorylation [56]. Under normal phosphorylation conditions, tau supports stabilizing the functions of microtubules on neuronal growth and axonal nutrient transport, while hyperphosphorylated tau loses its interactions with microtubules and prefers to aggregate with other tau molecules, forming neurofibrillary tangles inside neurons [56]. These neurofibrillary tangles consequently lead to microtubule dysfunction and blockage of the neuronal transport system, which damages the synaptic communications between neurons and AD-related brain changes [56]. And neurofibrillary tangles firstly found in the EC and hippocampus can extend to the amygdala and cortical areas (temporal, frontal, and parietal), causing more damage $[57,58]$.

The changes in $\mathrm{A} \beta$ oligomers and tau protein are reported by studies to be the most important factors for neuronal dysfunction in $\operatorname{AD}$ pathology $[59,60]$. And the strategies refer to decreasing phosphorylation degrees of tau.

In SweAPP N2a cells, the best caffeine treatment for suppression of GSK-3 $\beta$ levels was $20 \mu \mathrm{M}$ for 30 minutes, and a lower phosphorylation degree of tau was proposed [51] (Figure 1, Pathway 2). $0.3 \mathrm{~g} / \mathrm{l}$ of chronic caffeine delivery through drinking water $(4 \mu \mathrm{M}$ plasma caffeine) to THYTau22 mice (aged 2 months old) for 10 months was significantly associated with an increase in dephosphorylated tau protein at Tau1 pathologic epitopes by $36.4 \%( \pm 7.4 \%)$, as well as mitigated levels of proteolytic fragments of tau protein by reducing $\mathrm{N}$-terminal fragments by $40.9 \%( \pm 5.2 \%)$ and $\mathrm{C}$ terminal fragments by $54.8 \%( \pm 3.5 \%)$, as compared to 


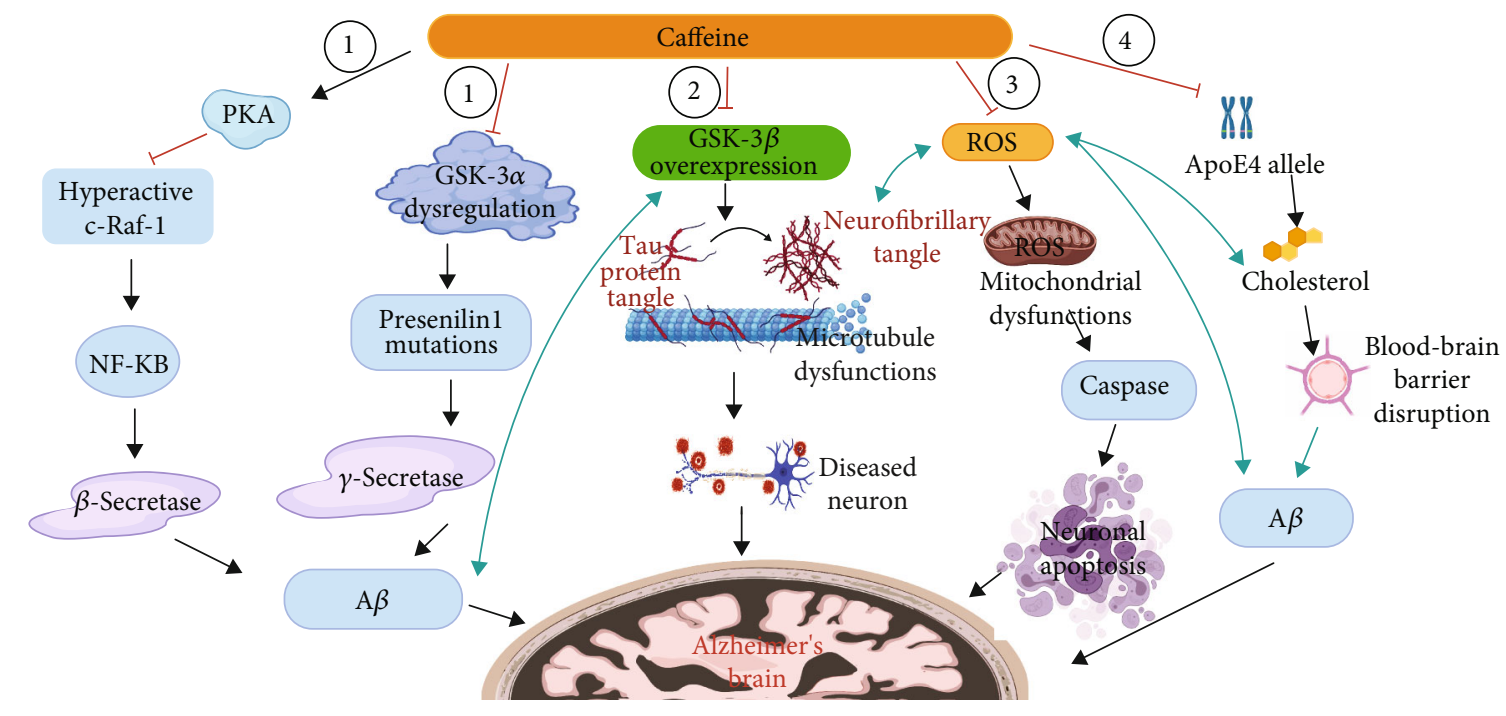

FIGURE 1: Caffeine neuroprotective mechanisms. (1) A $\beta$ theory contains two routes. Firstly, caffeine stimulates PKA activity that decreases the hyperactive form of $\mathrm{c}$-Raf- 1 . This abnormal c-Raf- 1 form supports $\mathrm{AD}$ progression by activating the NF- $\kappa \mathrm{B}$ pathway and $\beta$-secretase expression. Secondly, caffeine lowers the GSK-3 $\alpha$ dysregulation which increases PS1 mutation and $\gamma$-secretase expression. (2) Tau protein theory relates to the caffeine deactivating GSK- $3 \beta$ expression which can also be triggered by A $\beta$ that expedites tau hyperphosphorylation and neurofibrillary tangle formation inside neurons. (3) Oxidative stress theory shows that caffeine inhibits ROS formation which can be promoted by A $\beta$. ROS can impair the mitochondrial electron transport system, further triggering caspase and neuronal apoptosis. (4) ApoE4 theory shows that caffeine can decrease high plasma and astrocyte cholesterol levels induced by high ApoE4 levels and reduce BBB disruptions by hypercholesterolemia ( ${ }^{1}$ Adapted from "Pathology of Alzheimer's Disease", by BioRender.com (2021). Retrieved from https://app.biorender.com/ biorender-templates/t-5d8baeb4f7e1a5007dd46b18-pathology-of-alzheimers-disease/).

untreated THY-Tau22 mice [61]. Reduction of tau phosphorylation by caffeine is consistent with an in vitro model of cultured cortical neurons (SH-SY5Y cells) in the nonpathogenic context, with dosages of $20 \mathrm{mM}$ [62], which has been far higher than those achieved following habitual caffeine consumption (>10 mM) [63].

4.3. Oxidative Stress Theory. It is well understood that $\mathrm{AD}$ is strongly linked to extensive cellular OS [64]. OS is related to ROS accumulation in the brain because of inequality between ROS generation and antioxidant clearance activity [65]. The ROS could react quickly to biological components like lipid, leading to malfunction of the brain because the brain is mostly made up of a lipid that is easy to oxidize [65]. In addition, ROS could impair the mitochondrial electron transport system by disrupting its antioxidant enzyme functions, SOD1 and SOD2, causing a further increase in ROS levels that finally activate caspase and subsequently neuronal apoptosis [66] (Figure 1, Pathway 3 ). Also, OS could augment A $\beta$ production and aggregation and facilitate tau hyperphosphorylation, which, in turn, further promotes ROS formation [67]. Thus, treatment with antioxidant properties could protect neurons from oxidative stress and $\mathrm{A} \beta$ toxicity.

Caffeine can be the antioxidant to inhibit lipid peroxidation and mitigate OS by suppressing the production of ROS [65]. The use of $10 \mu \mathrm{M}$ caffeine treatment might reduce intracellular ROS by $40.36 \%$, increase SOD activity by $48.55 \%$, and decrease malondialdehyde by $44.29 \%$ of the SH-SY5Y cells which have been exposed to the combination of $\mathrm{A} \beta_{25-}$ ${ }_{35}$ and $\mathrm{AlCl}_{3}$ for $48 \mathrm{~h}$, and antiapoptotic $\mathrm{Bcl}-2$ protein levels for the prevention of neuronal death has been rescued
[68]. Furthermore, the number of caspase-3-positive neurons was reduced by $48 \%$ after $1.84 \mathrm{mg} / \mathrm{d}$ caffeine treatment (equivalent to daily human consumption of $4.86 \mathrm{mg} / \mathrm{kg}$ body weight of caffeine) as compared to cultures treated with only $20 \mu \mathrm{M}$ of $\mathrm{A} \beta_{25-35}$ for $48 \mathrm{~h}$, concurring the neuroprotective effects of caffeine against $\mathrm{A} \beta_{25-35^{-}}$ induced neuronal death [69].

4.4. ApoE4 Theory. ApoE4 is considered the largest genetic risk factor for $\mathrm{AD}$, with a prevalence of about $14 \%$, conferring a drastically elevated risk of $\mathrm{AD}$ with an earlier age of onset in a gene dose-dependent manner [70]. ApoE4 promotes the accumulation, aggregation, and deposition of $\mathrm{A} \beta$ in the brain. ApoE4 might be less efficient for clearing $A \beta$ in the $\mathrm{BBB}$ due to a lower affinity to $\mathrm{A} \beta$ than other ApoE isoforms (ApoE2, ApoE3) [70].

Besides, ApoE4 also generates aberrant brain cholesterol metabolism which can further increase $\mathrm{A} \beta$ generation and contribute to the $\mathrm{AD}$ risk [70]. ApoE is mainly produced by brain astrocytes, which account for up to $40 \%$ of all brain cells, and could carry the lipoprotein-bound cholesterol from circulating plasma to the brain, which has been regulated by the presence of $\mathrm{BBB}[70]$. ApoE4 is less efficient in transporting cholesterol from astrocytes to neurons and has a low binding capacity to plasma cholesterol [70]. Thus, high ApoE4 levels may lead to elevated cholesterol levels in the plasma and astrocytes [71]. And 2\% cholesterol-enriched diets could induce hypercholesterolemia in rabbits; 3 times higher levels of insoluble $\mathrm{A} \beta_{1-40}$ were achieved by increasing $\gamma$-secretase activity to cleave APP on the hippocampus [72]. Hypercholesterolemia has been associated with OS by 


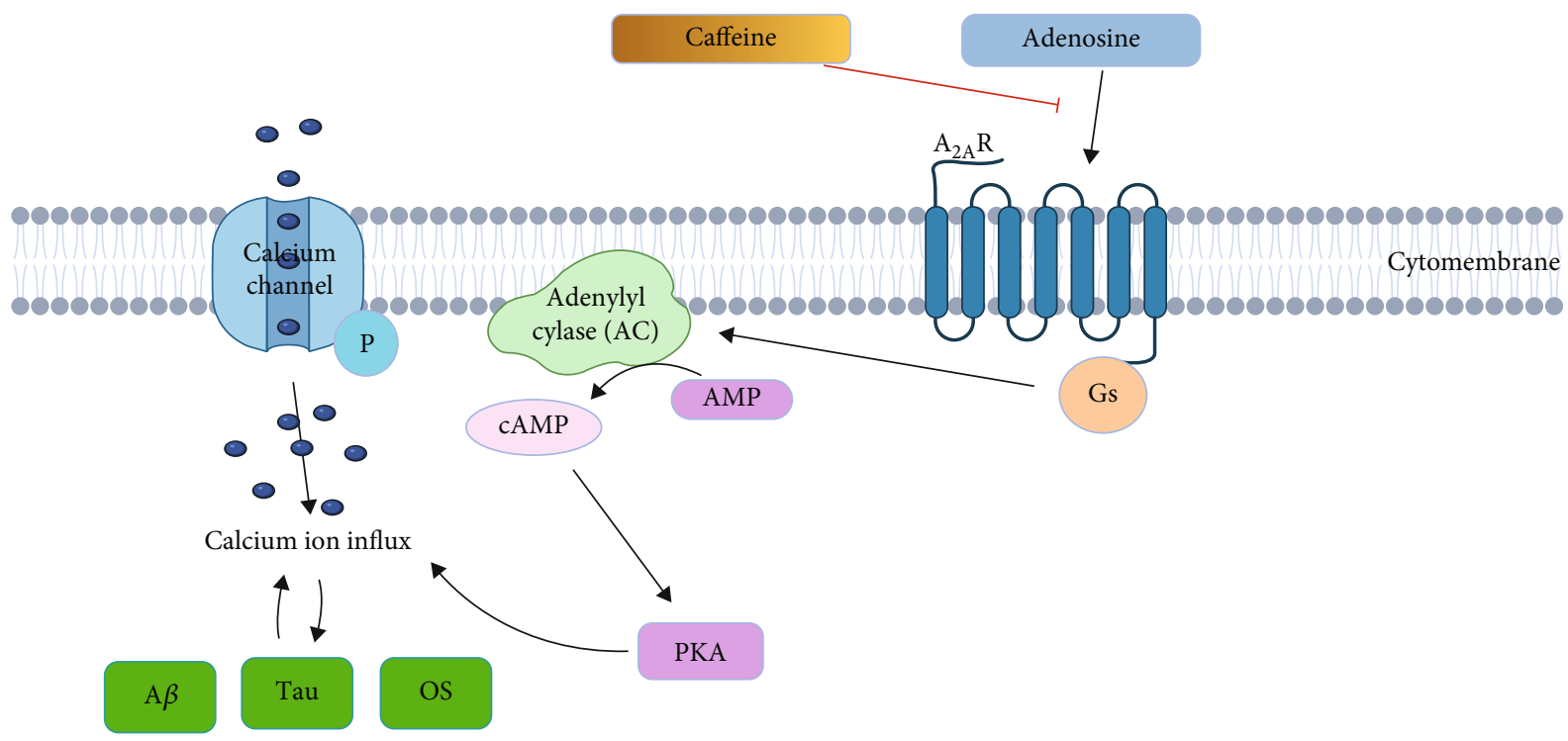

(a)

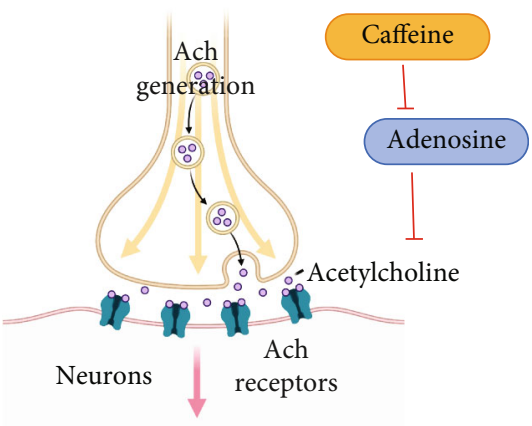

(b)

FIgURE 2: Caffeine intervenes with adenosine theory related to (a) lowering $\mathrm{A} \beta$ production by antagonizing $\mathrm{A}_{2 \mathrm{~A}} \mathrm{R}$ which can increase $\mathrm{AC}$ levels, cAMP and PKA activities, and overload of intracellular $\mathrm{Ca}^{2+}\left({ }^{2}\right.$ BioRender.com (2021). [Online]. Available from: https://app .biorender.com/user/signin/) and (b) inhibit adenosine functions on the decrease of neurotransmitter Ach expression (created with https:// biorender.com/ Created with BioRender.com. ${ }^{3}$ Adapted from "Neuromuscular Junction", by BioRender.com (2021). Retrieved fromhttps:// app.biorender.com/biorender-templates/t-5ed6b2d243ee8200b0135913-neuromuscular-junction/).

increasing ROS levels [72], and it could also disrupt BBB, increasing brain cholesterol levels further [73] (Figure 1, Pathway 4). Thus, strategies refer to reducing brain cholesterol accumulation.

$0.5 \mathrm{mg} / \mathrm{d}$ and $30 \mathrm{mg} / \mathrm{d}$ caffeine treatments for 12 weeks decreased cholesterol-induced $\mathrm{A} \beta$ accumulation and increased the phosphorylated tau and active form of enzyme GSK-3 $\beta$, as well as ROS generation in the hippocampus of rabbits (1.5-2 years old) which were daily fed a $2 \%$ cholesterol-enriched diet for 12 weeks. But the low caffeine dose $(0.5 \mathrm{mg} / \mathrm{d})$ was more efficient than the high dose $(30 \mathrm{mg} / \mathrm{d})$ in reducing $\mathrm{A} \beta_{40}$ and $\mathrm{A} \beta_{42}$ levels $(-33.64 \% \mathrm{com}-$ pared with $-22.62 \% ;-58.65 \%$ compared with $-45.46 \%$, respectively), which were reduced to similar levels as the control [72]. 12 weeks of $3 \mathrm{mg} / \mathrm{d}$ caffeine was given to rabbits aged 1.5 to 2 years, blocking the increased disruptions of $\mathrm{BBB}$ induced by the daily $2 \%$ cholesterol-enriched diet [73]. This was characterized by stabilization of the tight junctions between adjacent endothelial cells which involved an increase in expression of tight junction proteins includ- ing occludin and zonula occludens by $72.71 \%$ and $50.37 \%$, respectively [73].

4.5. Adenosine Theory. Aside from the common molecular pathogenesis of $\mathrm{AD}$ and associated theories, where many distinct factors interrelate, caffeine is largely linked to adenosine theory, which also interacts with other theories.

Adenosine is an endogenous neuroprotectant abundant in the CNS, and its extracellular concentrations rise considerably in response to brain damage, neuroinflammation, and aging [74]. Adenosine effects are mediated by interactions with $\mathrm{G}$ protein-coupled receptors called adenosine receptors, such as inhibitory $\mathrm{A}_{1} \mathrm{R}$ and excitatory $\mathrm{A}_{2 \mathrm{~A}} \mathrm{R}$ [75].

$A_{1} R$ is found in abundance in the neocortex, cerebellum, hippocampus, and dorsal horn of the spinal cord [76]. $A_{2 A} R$ is extensively expressed in the striatopallidal neurons and olfactory bulb, with lesser levels in other brain regions like the hippocampus [76]. Because low concentrations of adenosine prefer to act on the $A_{1} R$, while greater levels prefer to act on the $A_{2 A} R$, aging causes an imbalance in the expression of 


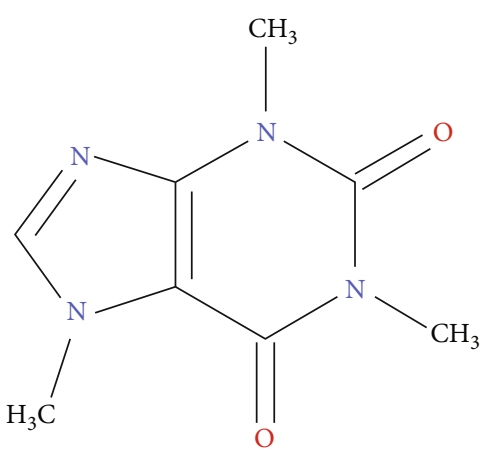

(a)

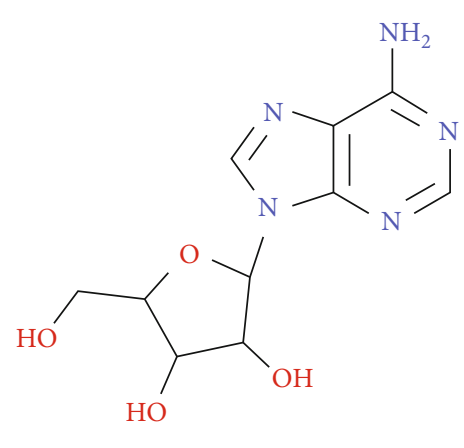

(b)

Figure 3: The chemical structure of caffeine (a) and adenosine (b) $\left({ }^{4}\right.$ KingDraw (2021). [Online]. Available from http://www.kingdraw.cn/en/ index.html/).

$A_{1} R$ and $A_{2 A} R$, contributing to cognitive impairment and an increased risk of $\mathrm{AD}[77,78]$. Meanwhile, adenosine lacks its inhibitory $\mathrm{A}_{1} \mathrm{R}$-mediated neuroprotective effects and ATP/adenosine metabolism in the aged brain but is modified to favor neurotransmission concerning stimulatory $A_{2 A} R$; a physiological cost may be suggested by an increased vulnerability of senescent neurons to excitatory amino acid toxicity and a decrease in the number of functioning synapses [79]. Of high interest, $\mathrm{A}_{2 \mathrm{~A}} \mathrm{R}$ antagonists, in particular, have been proposed to protect against cognitive and memory dysfunction evoked in experimental models of $\mathrm{AD}$ [41], independent of $\mathrm{A}_{1} \mathrm{R}$-mediated responses [80].

Furthermore, the activations and increased numbers of $A_{2 A} R$ increase their coupling to $G$ protein and efficacy in increasing AC levels, leading to AMP being converted to cAMP and higher levels of PKA. The calcium channels are more phosphorylated, resulting in an overload of intracellular $\mathrm{Ca}^{2+}[74]$, which stimulates $\mathrm{A} \beta$ and tau protein production and increases OS and neuroinflammation, ultimately contributing to increasing AD risk (Figure 2(a)) [64]. Also, the $\mathrm{A} \beta$ may promote overload of cellular calcium by inducing membrane-related OS and forming pores in the membrane [81]. Furthermore, the cholinergic and adenosinergic systems in the aged brain have an inverse relationship, with key neurotransmitter Ach levels in the brain declining with age while adenosine levels rise [82]. And because adenosine inhibits the release of Ach [83], adenosine accumulation has been linked to the progression of age-related cognitive deficits, making it an attractive target for pharmaceutical intervention (Figure 2(b)).

Caffeine, a well-known neuromodulator with an associative effect on cognitive performance, is structurally similar to adenosine due to purine backbones (Figure 3), which compete with the actions of adenosine as a nonselective $A_{2 \mathrm{~A}} \mathrm{R}$ antagonist [84].

Subchronic administration of daily $30 \mathrm{mg} / \mathrm{kg}$ caffeine for 4 days to mice (3-4 months old, $35-45 \mathrm{~g}$ ) (the equivalent of 360-540 mg of caffeine) prevented $\mathrm{A} \beta_{25-35}$-induced amnesic effects [84], extending the finding that $25 \mu \mathrm{M}$ caffeine fully prevented the death of cultured cerebellar granule neurons of rats caused by the $\mathrm{A} \beta_{25-35}$ through stimulating the cholinergic neurotransmission [85]. Chronic administration of high amounts of caffeine $(100 \mathrm{mg} / \mathrm{kg} / \mathrm{d})$ to mice $(25-30 \mathrm{~g})$ for 4 days resulted in a $40-50 \%$ increase in the density of cholinergic, muscarinic, and nicotinic receptors in the brain and may also have augmented cholinergic activity, which facilitated disruptions in the progression of $\mathrm{AD}$ [86].

Based on data collected from animal models and cell lines, chronic caffeine administration or other pharmacological agents that mimic caffeine in moderate amounts (200$500 \mathrm{mg} / \mathrm{d}$ ) at midlife would have therapeutic potential in the $\mathrm{AD}$ treatment later in life according to five theories, especially attenuating the $\mathrm{A} \beta$ burden and $\mathrm{A} \beta$-induced neurotoxicity. Even experimental studies indicate rather favorable effects of caffeine; such benefits may not be fully relevant to $\mathrm{AD}$ in humans, particularly when high dosages were used, necessitating us to carefully analyze and conduct more welldefined human studies to evaluate the role of caffeine on $\mathrm{AD}$ treatment. Meanwhile, a meta-analysis of diverse animal models also found that the effects of caffeine and $\mathrm{A}_{2 \mathrm{~A}} \mathrm{R}$ antagonists are mostly determined by the dose, the schedule and time of administration, and the method of administration [87]. Moderate dosages of caffeine have been shown to increase memory function in mice [88-90], whereas greater doses of caffeine have been shown to damage memory acquisition $[91,92]$.

\section{Conclusions}

In conclusion, based on the results of epidemiological and experimental studies, moderate and regular caffeine consumption may help to prevent or delay the onset of $\mathrm{AD}$ and may be a viable therapeutic approach. However, before conducting rigorous preclinical and clinical research on its therapeutic potential in terms of precise neuroprotective dosages, frequencies, and durations, this recommendation would be premature. And to answer conflicting results in some human studies, the future study is required to set international consensual criteria for outcome measure, apply multivariate analyses to manage various confounding risk factors, clarify the drinking history of coffee and tea in the self-reported questionnaires, recruit a large number of participants from multiethnic backgrounds, and conduct a long follow-up period. 
Meanwhile, as long as caffeine intake is maintained daily (e.g., tolerance), moderate usage of caffeine is usually not associated with harmful side effects. Although caffeine has been suspected of causing hypertension, there is no association between caffeine consumption in coffee or/and tea and blood pressure. Given the already widespread use and acceptance of coffee in moderate amounts, long-term coffee intake could be a viable strategy for reducing the risk of $\mathrm{AD}$. However, more research into the effects of tea consumption on the risk of $\mathrm{AD}$ is needed.

\section{Abbreviations}

AD:
CNS:
mg/d:
wk:
OR:
CI:
RR:
$I^{2}$ :
HR:
MMSE:

MMSE-r: m-MMSE:

$B:$

SE:

Alzheimer's disease

Central nervous system

Milligram per day

Week

Odds ratio

Confidence interval

Relative risk

Heterogeneity

Hazard ratio

Mini-Mental State Examination

(higher MMSE scores mean higher

cognitive function), which measures

global cognition including memory,

attention, language, praxis, and visuospatial ability [24]

A modified version of the Mini-Mental

State Examination

State Examination

Regression coefficient

NINCDS-ADRDA: National Institute of Neurological and Communicative Disorders and Stroke and the Alzheimer's Disease and

Related Disorders Association

BMI: Body mass index

HAAS Programme: Honolulu-Asia Aging prospective cohort Study Programme

CLHLS:

CAIDE:

Chinese Longitudinal Health Longevity Study

SBP:

MI:

DM:

CSHA:

MEC:

SIMPLER:

Cardiovascular Risk Factors, Aging and Dementia

Systolic blood pressure

Myocardial infarction

Diabetes mellitus

Canadian Study of Health and Aging

Multiethnic cohort

Swedish Infrastructure for Medical

Population-based Life-course Environmental Research, previously the Swedish Mammography Cohort and the Cohort of Swedish Men

SLAS:

HUSK:

Singapore Longitudinal Aging Study

CASI:

Hordaland Health Study

Cognitive Abilities Screening

Instrument

ICD:

Codes from the International Classifi-
ICD-9:
ICD-10:
3MS:

d:

USA:

N/A:

CVD:

BBB:

$\mathrm{Ca}^{2+}$ :

EGCG:

A $\beta$ peptides:

NFTs:

ApoE:

APP:

$\beta$-Secretase:

$\gamma$-Secretase:

APPsw:

PKA:

NF- $\kappa$ B:

GSK-3:

EC:

OS:

ROS:

SOD1:

SOD2:

Ach:

$\mathrm{A}_{1} \mathrm{R}$ :

$\mathrm{A}_{2 \mathrm{~A}} \mathrm{R}$ :

AC:

cAMP:

Tg:

PS1:

THY-Tau22:

Malondialdehyde:

\section{Data Availability}

After electronic searches on databases PubMed and ScienceDirect, potential eligible studies from 2000 up until 2020 have been identified. According to instructions in Boolean operators and wildcards, the searches applied the following terms to clarify dietary risk factors (coffee OR tea OR caffeine) combined with terms of interested results (cognit* AND (declin* OR damag*)) or (neurodegenerat* OR Alzheimer*). The range of obtained results is around 2000 records. After scanning titles, keywords, and the gist of abstracts in each article, the articles were retained for close reading and analysis of details if all of the following inclusion criteria are met: (1) the published paper had full length and was in a peerreviewed source; (2) it evaluated caffeine which was sourced

\author{
Ninth revision \\ Tenth revision \\ Examination \\ The United States of America \\ None/anonymity \\ Blood-brain barrier \\ Amyloid beta peptides \\ Neurofibrillary tangles \\ Apolipoprotein E \\ Beta-secretase \\ Gamma-secretase \\ Swedish mutation \\ Protein kinase A \\ enhancer of activated B cells \\ Glycogen synthase kinase-3 \\ Entorhinal cortex \\ xidative stress \\ Reactive oxygen species \\ Superoxide dismutase 2 \\ Acetylcholine \\ Adenosine $\mathrm{A}_{1}$ receptor \\ Adenosine $\mathrm{A}_{2 \mathrm{~A}}$ receptor \\ Aenylyl cyclase \\ Transgenic \\ Presenilin 1 \\ expression in the hippocampal forma- \\ tion with a small cortex pathology and \\ no significant spinal cord pathology, \\ making it a reliable model for assessing \\ the modeling effects on hippocampal \\ effects on behavior and plasticity [61] \\ A marker of oxidative stress.
} cation of Diseases 
from caffeine, coffee, or tea; and (3) it mentioned AD, cognitive impairment, or cognitive decline. And a study was excluded if it met one or more of the following exclusion criteria: (1) the published paper was in a non-peer-reviewed source (i.e., website, magazines); (2) it was in the abstract form; (3) the investigational product was not caffeine, coffee, or tea; (4) it investigated diseases which were not related to cognitive disorders; and (5) it was a duplicate publication. In addition, the present article included several secondary research papers (i.e., narrative review, systemic review, and meta-analysis studies) which could recommend other relevant research studies with the same topics after looking through their reference lists as key clues. Articles in which caffeine was not studied were excluded. Articles, where sources of caffeine were not from coffee or tea, were excluded. Also, articles in which cognitive decline or Alzheimer's disease was not mentioned were excluded as well. Researchers paid deliberate attention to papers which concluded human studies or animal studies for neuroprotective effects of caffeine for approving arguments as well as theories behind the pathogenesis of neurodegenerative diseases. This paper focused on the prevention and postponement of progression of age-related neurodegenerative diseases; thus, analyses ignored cognitive decline within the normal range. And articles concerning the dosage and frequency of coffee and tea consumption were selected to have a deep analysis for comparing the difference between coffee and tea. This article includes both single studies like longitudinal studies and meta-analyses for more prudent considerations.

\section{Conflicts of Interest}

This study does not have any conflicts of interest.

\section{Authors' Contributions}

Xiangyu Zhou and Lin Zhang contributed equally to this work.

\section{Acknowledgments}

This study was supported by the Hunan Key Laboratory for Processing of Special Medicine Food (2017TP1021) and Hunan key research and development plan project (2020NK2020). Figures 1 and 2 are created with https:// biorender.com/. Figure 3 is created with http://kingdraw .com/.

\section{References}

[1] S. Ray and S. Davidson, "Dementia and cognitive decline. A review of the evidence," Age UK, vol. 27, pp. 10-12, 2014.

[2] B. D. James and J. A. Schneider, "Increasing incidence of dementia in the oldest old: evidence and implications," Alzheimer's Research \& Therapy, vol. 2, no. 3, pp. 9-12, 2010.

[3] R. C. Petersen, G. E. Smith, S. C. Waring, R. J. Ivnik, E. G. Tangalos, and E. Kokmen, "Mild cognitive impairment: clinical characterization and outcome," Archives of Neurology, vol. 56, no. 3, pp. 303-308, 1999.
[4] T.-P. Ng, L. Feng, M. Niti, E. H. Kua, and K. B. Yap, "Tea consumption and cognitive impairment and decline in older Chinese adults," The American Journal of Clinical Nutrition, vol. 88, no. 1, pp. 224-231, 2008.

[5] Y.-S. Kim, S. M. Kwak, and S.-K. Myung, "Caffeine intake from coffee or tea and cognitive disorders: a meta-analysis of observational studies," Neuroepidemiology, vol. 44, no. 1, pp. 51-63, 2015.

[6] C. Patterson, J. W. Feightner, A. Garcia, G. Y. R. Hsiung, C. MacKnight, and A. D. Sadovnick, "Diagnosis and treatment of dementia. 1. Risk assessment and primary prevention of Alzheimer disease," CMAJ, vol. 178, no. 5, pp. 548-556, 2008.

[7] K. Deckers, M. P. J. van Boxtel, O. J. G. Schiepers et al., “Target risk factors for dementia prevention: a systematic review and Delphi consensus study on the evidence from observational studies," International Journal of Geriatric Psychiatry, vol. 30, no. 3, pp. 234-246, 2015.

[8] X. Du, X. Wang, and M. Geng, "Alzheimer's disease hypothesis and related therapies," Translational neurodegeneration, vol. 7, no. 1, pp. 1-7, 2018.

[9] J. A. Watt, Z. Goodarzi, A. A. Veroniki et al., "Comparative efficacy of interventions for aggressive and agitated behaviors in dementia: a systematic review and network meta-analysis," Annals of Internal Medicine, vol. 171, no. 9, pp. 633-642, 2019.

[10] M. J. R. Howes, N. S. L. Perry, C. Vásquez-Londoño, and E. K. Perry, "Role of phytochemicals as nutraceuticals for cognitive functions affected in ageing," British Journal of Pharmacology, vol. 177, no. 6, pp. 1294-1315, 2020.

[11] N. Scarmeas, C. A. Anastasiou, and M. Yannakoulia, "Nutrition and prevention of cognitive impairment," The Lancet Neurology, vol. 17, no. 11, pp. 1006-1015, 2018.

[12] P. Londzin, M. Zamora, B. Kąkol, A. Taborek, and J. Folwarczna, "Potential of caffeine in Alzheimer's disease-a review of experimental studies," Nutrients, vol. 13, no. 2, p. 537, 2021.

[13] M. A. Heckman, J. Weil, and E. G. De Mejia, "Caffeine (1, 3, 7trimethylxanthine) in foods: a comprehensive review on consumption, functionality, safety, and regulatory matters," Journal of Food Science, vol. 75, no. 3, pp. R77-R87, 2010.

[14] G. Sutherland, J. Peeling, H. J. Lesiuk et al., "The effects of caffeine on ischemic neuronal injury as determined by magnetic resonance imaging and histopathology," Neuroscience, vol. 42, no. 1, pp. 171-182, 1991.

[15] K. Rudolphi, M. Keil, J. Fastbom, and B. B. Fredholm, "Ischaemic damage in gerbil hippocampus is reduced following upregulation of adenosine $\left(\mathrm{A}_{1}\right)$ receptors by caffeine treatment," Neuroscience Letters, vol. 103, no. 3, pp. 275-280, 1989.

[16] K. A. Rudolphi and P. Schubert, "Modulation of neuronal and glial cell function by adenosine and neuroprotection in vascular dementia," Behavioural Brain Research, vol. 83, no. 1-2, pp. 123-128, 1997.

[17] A. Nehlig, "Are we dependent upon coffee and caffeine? A review on human and animal data," Neuroscience \& Biobehavioral Reviews, vol. 23, no. 4, pp. 563-576, 1999.

[18] C. Cabrera, R. Artacho, and R. Giménez, "Beneficial effects of green tea-a review," Journal of the American College of Nutrition, vol. 25, no. 2, pp. 79-99, 2006.

[19] J. Conway, Number of cups of tea Canadian consumers drink on an average day 2019, Statista, 2020.

[20] J. Lindsay, D. Laurin, R. Verreault et al., "Risk factors for Alzheimer's disease: a prospective analysis from the Canadian 
Study of Health and Aging," American Journal of Epidemiology, vol. 156, no. 5, pp. 445-453, 2002.

[21] E. Nurk, H. Refsum, C. A. Drevon et al., "Intake of flavonoidrich wine, tea, and chocolate by elderly men and women is associated with better cognitive test performance," The Journal of Nutrition, vol. 139, no. 1, pp. 120-127, 2009.

[22] L. Maia and A. De Mendonça, "Does caffeine intake protect from Alzheimer's disease?," European Journal of Neurology, vol. 9, no. 4, pp. 377-382, 2002.

[23] R. P. Gelber, H. Petrovitch, K. H. Masaki, G. W. Ross, and L. R. White, "Coffee intake in midlife and risk of dementia and its neuropathologic correlates," Journal of Alzheimer's Disease, vol. 23, no. 4, pp. 607-615, 2011.

[24] C. Santos, J. Costa, J. Santos, A. Vaz-Carneiro, and N. Lunet, "Caffeine intake and dementia: systematic review and metaanalysis," Journal of Alzheimer's Disease, vol. 20, Supplement 1, pp. S187-S204, 2010.

[25] M. H. Eskelinen, T. Ngandu, J. Tuomilehto, H. Soininen, and M. Kivipelto, "Midlife coffee and tea drinking and the risk of late-life dementia: a population-based CAIDE study," Journal of Alzheimer's Disease, vol. 16, no. 1, pp. 85-91, 2009.

[26] J. Conway, Number of cups of coffee consumed per day among coffee drinkers in Canada 2008-2020, Statista, 2021.

[27] S.-Y. Park, N. D. Freedman, C. A. Haiman, L. le Marchand, L. R. Wilkens, and V. W. Setiawan, "Association of coffee consumption with total and cause-specific mortality among nonwhite populations," Annals of Internal Medicine, vol. 167, no. 4, pp. 228-235, 2017.

[28] S. C. Larsson and A. Wolk, "The role of lifestyle factors and sleep duration for late-onset dementia: a cohort study," Journal of Alzheimer's Disease, vol. 66, no. 2, pp. 579-586, 2018.

[29] J. L. B. Quintana, M. F. Allam, A. S. del Castillo, and R. F. C. Navajas, "Alzheimer's disease and coffee: a quantitative review," Neurological Research, vol. 29, no. 1, pp. 91-95, 2007.

[30] X. Chen, Y. Huang, and H. Cheng, "Lower intake of vegetables and legumes associated with cognitive decline among illiterate elderly Chinese: a 3-year cohort study," The Journal of Nutrition, Health \& Aging, vol. 16, no. 6, pp. 549-552, 2012.

[31] S. Kuriyama, A. Hozawa, K. Ohmori et al., "Green tea consumption and cognitive function: a cross-sectional study from the Tsurugaya Project," The American Journal of Clinical Nutrition, vol. 83, no. 2, pp. 355-361, 2006.

[32] L. Feng, X. Gwee, E. . H. Kua, and T. . P. Ng, "Cognitive function and tea consumption in community dwelling older Chinese in Singapore," The Journal of Nutrition, Health \& Aging, vol. 14, no. 6, pp. 433-438, 2010.

[33] Q.-P. Ma, C. Huang, Q. Y. Cui et al., "Meta-analysis of the association between tea intake and the risk of cognitive disorders," PLoS One, vol. 11, no. 11, article e0165861, 2016.

[34] S. Cappelletti, P. Daria, G. Sani, and M. Aromatario, "Caffeine: cognitive and physical performance enhancer or psychoactive drug?," Current Neuropharmacology, vol. 13, no. 1, pp. 71-88, 2015.

[35] S. Kakutani, H. Watanabe, and N. Murayama, "Green tea intake and risks for dementia, Alzheimer's disease, mild cognitive impairment, and cognitive impairment: a systematic review," Nutrients, vol. 11, no. 5, p. 1165, 2019.

[36] G. S. Watson and S. Craft, "The role of insulin resistance in the pathogenesis of Alzheimer's disease," CNS Drugs, vol. 17, no. 1, pp. 27-45, 2003.
[37] S. Molino, M. Dossena, D. Buonocore et al., "Polyphenols in dementia: from molecular basis to clinical trials," Life Sciences, vol. 161, pp. 69-77, 2016.

[38] Y. Kataoka, K. Utsunomiya, A. Kimbara et al., "Preventive effect of green tea containing theanine at a high concentration on dementia in aged volunteers," The Journal of Japan Mibyou System Association, vol. 15, pp. 17-23, 2009.

[39] M. Arnaud, "The pharmacology of caffeine," Progress in drug research/Fortschritte der Arzneimittelforschung/Progrès des recherches pharmaceutiques, vol. 31, pp. 273-313, 1987.

[40] S. Teekachunhatean, N. Tosri, N. Rojanasthien, S. Srichairatanakool, and C. Sangdee, "Pharmacokinetics of caffeine following a single administration of coffee enema versus oral coffee consumption in healthy male subjects," International Scholarly Research Notices, vol. 2013, Article ID 147238, 7 pages, 2013.

[41] G. Arendash, W. Schleif, K. Rezai-Zadeh et al., "Caffeine protects Alzheimer's mice against cognitive impairment and reduces brain $\beta$-amyloid production," Neuroscience, vol. 142, no. 4, pp. 941-952, 2006.

[42] B. B. Fredholm, "Adenosine, adenosine receptors and the actions of caffeine," Pharmacology \& Toxicology, vol. 76, no. 2, pp. 93-101, 1995.

[43] T. C. Theoharides, Essentials of Pharmacology, Little Brown \& Company, 1996.

[44] M. Cheng, Z. Hu, X. Lu, J. Huang, and D. Gu, "Caffeine intake and atrial fibrillation incidence: dose response meta-analysis of prospective cohort studies," Canadian Journal of Cardiology, vol. 30, no. 4, pp. 448-454, 2014.

[45] A. D. Gitler, P. Dhillon, and J. Shorter, Neurodegenerative disease: models, mechanisms, and a new hope, The Company of Biologists Ltd, 2017.

[46] M. Prince, A. Wimo, M. Guerchet, G. C. Ali, Y. T. Wu, and M. Prina, The global impact of dementia: an analysis of prevalence, incidence, cost and trends, World Alzheimer Report, 2015, 2015.

[47] M. P. Murphy and H. LeVine III, “Alzheimer's disease and the amyloid- $\beta$ peptide," Journal of Alzheimer's Disease, vol. 19, no. 1, pp. 311-323, 2010.

[48] P. Rajendran, A. Bhatt, S. Manthuruthil, and S. Pericherla, "Caffeine and Alzheimer's disease," International Journal of Biological and Medical Research, vol. 3, pp. 3513-3514, 2013.

[49] E. Mohandas, V. Rajmohan, and B. Raghunath, "Neurobiology of Alzheimer's disease," Indian Journal of Psychiatry, vol. 51, no. 1, pp. 55-61, 2009.

[50] G. W. Arendash, M. F. Garcia, D. A. Costa, J. R. Cracchiolo, I. M. Wefes, and H. Potter, "Environmental enrichment improves cognition in aged Alzheimer's transgenic mice despite stable $\beta$-amyloid deposition," Neuroreport, vol. 15, no. 11, pp. 1751-1754, 2004.

[51] G. W. Arendash, T. Mori, C. Cao et al., "Caffeine reverses cognitive impairment and decreases brain amyloid- $\beta$ levels in aged Alzheimer's disease mice," Journal of Alzheimer's Disease, vol. 17, no. 3, pp. 661-680, 2009.

[52] C. J. Phiel, C. A. Wilson, V. M. Y. Lee, and P. S. Klein, “GSK-3 $\alpha$ regulates production of Alzheimer's disease amyloid- $\beta$ peptides," Nature, vol. 423, no. 6938, pp. 435-439, 2003.

[53] P. Fuentes G and A. Slachevsky Ch, "Enfermedad de Alzheimer: Actualización en terapia farmacológica," Revista Médica de Chile, vol. 133, no. 2, pp. 224-230, 2005. 
[54] W.-H. Zheng, S. Bastianetto, F. Mennicken, W. Ma, and S. Kar, "Amyloid $\beta$ peptide induces tau phosphorylation and loss of cholinergic neurons in rat primary septal cultures," Neuroscience, vol. 115, no. 1, pp. 201-211, 2002.

[55] J. J. Lucas, F. Hernández, P. Gómez-Ramos, M. A. Morán, R. Hen, and J. Avila, "Decreased nuclear beta-catenin, tau hyperphosphorylation and neurodegeneration in GSK-3beta conditional transgenic mice," The EMBO Journal, vol. 20, no. 1, pp. 27-39, 2001.

[56] K. Iqbal, F. Liu, C. X. Gong, and I. Grundke-Iqbal, “Tau in Alzheimer disease and related tauopathies," Current Alzheimer Research, vol. 7, no. 8, pp. 656-664, 2010.

[57] M. Goedert and M. G. Spillantini, “A century of Alzheimer's disease,” Science, vol. 314, no. 5800, pp. 777-781, 2006.

[58] M. S. Rafii and P. S. Aisen, "Recent developments in Alzheimer's disease therapeutics," BMC Medicine, vol. 7, no. 1, pp. 1-4, 2009.

[59] W. H. Stoothoff and G. V. Johnson, "Tau phosphorylation: physiological and pathological consequences," Biochimica et Biophysica Acta (BBA)-Molecular Basis of Disease, vol. 1739, no. 2-3, pp. 280-297, 2005.

[60] B. De Strooper, "Proteases and proteolysis in Alzheimer disease: a multifactorial view on the disease process," Physiological Reviews, vol. 90, no. 2, pp. 465-494, 2010.

[61] C. Laurent, S. Eddarkaoui, M. Derisbourg et al., "Beneficial effects of caffeine in a transgenic model of Alzheimer's disease-like tau pathology," Neurobiology of Aging, vol. 35, no. 9, pp. 2079-2090, 2014.

[62] A. Currais, K. Kato, L. Canuet et al., "Caffeine modulates tau phosphorylation and affects Akt signaling in postmitotic neurons," Journal of Molecular Neuroscience, vol. 43, no. 3, pp. 326-332, 2011.

[63] B. B. Fredholm, K. Bättig, J. Holmén, A. Nehlig, and E. E. Zvartau, "Actions of caffeine in the brain with special reference to factors that contribute to its widespread use," Pharmacological Reviews, vol. 51, no. 1, pp. 83-133, 1999.

[64] M. T. Lin and M. F. Beal, "Mitochondrial dysfunction and oxidative stress in neurodegenerative diseases," Nature, vol. 443, no. 7113, pp. 787-795, 2006.

[65] W. J. Huang, X. Zhang, and W. W. Chen, "Role of oxidative stress in Alzheimer's disease," Biomedical Reports, vol. 4, no. 5, pp. 519-522, 2016.

[66] P. I. Moreira, C. Carvalho, X. Zhu, M. A. Smith, and G. Perry, "Mitochondrial dysfunction is a trigger of Alzheimer's disease pathophysiology," Biochimica et Biophysica Acta (BBA)-Molecular Basis of Disease, vol. 1802, no. 1, pp. 210, 2010.

[67] G. F. Makhaeva, S. V. Lushchekina, N. P. Boltneva et al., "Conjugates of $\gamma$-carbolines and phenothiazine as new selective inhibitors of butyrylcholinesterase and blockers of NMDA receptors for Alzheimer disease," Scientific Reports, vol. 5, no. 1, pp. 1-11, 2015.

[68] S. Giunta, V. Andriolo, and A. Castorina, "Dual blockade of the $A_{1}$ and $A_{2 A}$ adenosine receptor prevents amyloid beta toxicity in neuroblastoma cells exposed to aluminum chloride," The International Journal of Biochemistry \& Cell Biology, vol. 54, pp. 122-136, 2014.

[69] Y.-F. Chu, W. H. Chang, R. M. Black et al., "Crude caffeine reduces memory impairment and amyloid $\beta_{1-42}$ levels in an Alzheimer's mouse model," Food Chemistry, vol. 135, no. 3, pp. 2095-2102, 2012.
[70] C.-C. Liu, C. C. Liu, T. Kanekiyo, H. Xu, and G. Bu, “Apolipoprotein $\mathrm{E}$ and Alzheimer disease: risk, mechanisms and therapy," Nature Reviews Neurology, vol. 9, no. 2, pp. 106-118, 2013.

[71] E. Boerwinkle and G. Utermann, "Simultaneous effects of the apolipoprotein E polymorphism on apolipoprotein E, apolipoprotein B, and cholesterol metabolism," American Journal of Human Genetics, vol. 42, no. 1, pp. 104-112, 1988.

[72] J. R. Prasanthi, B. Dasari, G. Marwarha et al., "Caffeine protects against oxidative stress and Alzheimer's disease-like pathology in rabbit hippocampus induced by cholesterolenriched diet," Free Radical Biology and Medicine, vol. 49, no. 7, pp. 1212-1220, 2010.

[73] X. Chen, J. W. Gawryluk, J. F. Wagener, O. Ghribi, and J. D. Geiger, "Caffeine blocks disruption of blood brain barrier in a rabbit model of Alzheimer's disease," Journal of Neuroinflammation, vol. 5, no. 1, pp. 12-14, 2008.

[74] R. B. Dias, D. M. Rombo, J. A. Ribeiro, J. M. Henley, and A. M. Sebastião, "Adenosine: setting the stage for plasticity," Trends in Neurosciences, vol. 36, no. 4, pp. 248-257, 2013.

[75] S. Moro, F. Deflorian, G. Spalluto et al., "Demystifying the three dimensional structure of $G$ protein-coupled receptors (GPCRs) with the aid of molecular modeling," Chemical Communications, vol. 24, no. 24, pp. 2949-2956, 2003.

[76] J. Sawynok, "Adenosine receptor targets for pain," Neuroscience, vol. 338, pp. 1-18, 2016.

[77] T. Almeida, R. J. Rodrigues, A. de Mendonça, J. A. Ribeiro, and R. A. Cunha, "Purinergic P2 receptors trigger adenosine release leading to adenosine $\mathrm{A}_{2 \mathrm{~A}}$ receptor activation and facilitation of long-term potentiation in rat hippocampal slices," Neuroscience, vol. 122, no. 1, pp. 111-121, 2003.

[78] R. A. Cunha, P. Correia-de-Sá, A. M. Sebastião, and J. A. Ribeiro, "Preferential activation of excitatory adenosine receptors at rat hippocampal and neuromuscular synapses by adenosine formed from released adenine nucleotides," British Journal of Pharmacology, vol. 119, no. 2, pp. 253260, 1996.

[79] R. A. Cunha, T. Almeida, and J. Ribeiro, "Parallel modification of adenosine extracellular metabolism and modulatory action in the hippocampus of aged rats," Journal of Neurochemistry, vol. 76, no. 2, pp. 372-382, 2001.

[80] L. V. Lopes, R. A. Cunha, and J. Ribeiro, "Increase in the number, $G$ protein coupling, and efficiency of facilitatory adenosine A2A receptors in the limbic cortex, but not striatum, of aged rats," Journal of Neurochemistry, vol. 73, no. 4, pp. 17331738, 1999.

[81] A. Sanabria-Castro, I. Alvarado-Echeverría, and C. MongeBonilla, "Molecular pathogenesis of Alzheimer's disease: an update," Annals of Neurosciences, vol. 24, no. 1, pp. 46-54, 2017.

[82] B. Sperlágh, G. Zsilla, M. Baranyi, A. Kékes-Szabó, and E. S. Vizi, "Age-dependent changes of presynaptic neuromodulation via A1-adenosine receptors in rat hippocampal slices," International Journal of Developmental Neuroscience, vol. 15, no. 6, pp. 739-747, 1997.

[83] C. Corsi, M. Pazzagli, L. Bianchi, L. D. Corte, G. Pepeu, and F. Pedata, "In vivo amino acid release from the striatum of aging rats: adenosine modulation," Neurobiology of Aging, vol. 18, no. 2, pp. 243-250, 1997.

[84] O. P. Dall'Igna, P. Fett, M. W. Gomes, D. O. Souza, R. A. Cunha, and D. R. Lara, "Caffeine and adenosine $\mathrm{A}_{2 \mathrm{a}}$ receptor 
antagonists prevent $\beta$-amyloid (25-35)-induced cognitive deficits in mice," Experimental Neurology, vol. 203, no. 1, pp. 241245, 2007.

[85] O. P. Dall'lgna, L. O. Porciúncula, D. O. Souza, R. A. Cunha, and D. R. Lara, "Neuroprotection by caffeine and adenosine A2A receptor blockade of $\beta$-amyloid neurotoxicity," British Journal of Pharmacology, vol. 138, no. 7, pp. 1207-1209, 2003.

[86] D. Shi, O. Nikodijević, K. A. Jacobson, and J. W. Daly, "Chronic caffeine alters the density of adenosine, adrenergic, cholinergic, GABA, and serotonin receptors and calcium channels in mouse brain," Cellular and Molecular Neurobiology, vol. 13, no. 3, pp. 247-261, 1993.

[87] R. N. Takahashi, F. A. Pamplona, and R. Prediger, "Adenosine receptor antagonists for cognitive dysfunction: a review of animal studies," Frontiers in Bioscience, vol. 13, no. 13, pp. 26142632, 2008.

[88] M. Angelucci, C. Cesário, R. H. Hiroi, P. L. Rosalen, and C. D. Cunha, "Effects of caffeine on learning and memory in rats tested in the Morris water maze," Brazilian Journal of Medical and Biological Research, vol. 35, no. 10, pp. 1201-1208, 2002.

[89] M. Costa, P. H. Botton, S. Mioranzza, D. O. Souza, and L. O. Porciúncula, "Caffeine prevents age-associated recognition memory decline and changes brain- derived neurotrophic factor and tirosine kinase receptor (TrkB) content in mice," Neuroscience, vol. 153, no. 4, pp. 1071-1078, 2008.

[90] R. D. Prediger, L. C. Batista, and R. N. Takahashi, "Caffeine reverses age-related deficits in olfactory discrimination and social recognition memory in rats:," Neurobiology of Aging, vol. 26, no. 6, pp. 957-964, 2005.

[91] M. E. Angelucci, M. A. B. F. Vital, C. Cesário, C. R. Zadusky, P. L. Rosalen, and C. da Cunha, "The effect of caffeine in animal models of learning and memory," European Journal of Pharmacology, vol. 373, no. 2-3, pp. 135-140, 1999.

[92] K. P. Corodimas, J. M. Stieg, and J. C. Pruitt, "Acute exposure to caffeine selectively disrupts context conditioning in rats," Psychopharmacology, vol. 152, no. 4, pp. 376-382, 2000. 